\title{
Meta-analysis in Psychological Research.
}

\author{
El meta-análisis en la investigación psicológica. \\ Julio Sánchez-Meca and Fulgencio Marín-Martínez \\ University of Murcia, Spain
}

\begin{abstract}
Meta-analysis is a research methodology that aims to quantitatively integrate the results of a set of empirical studies about a given topic. With this purpose, effect-size indices are obtained from the individual studies and the characteristics of the studies are coded in order to examine their relationships with the effect sizes. Statistical analysis in meta-analysis requires the weighting of each effect estimate as a function of its precision, by assuming a fixed- or a randomeffects model. This paper outlines the steps required for carrying out the statistical analyses in a meta-analysis, the different statistical models that can be assumed, and the consequences of the assumptions in interpreting their results. The statistical analyses are illustrated with a real example.
\end{abstract}

Key words: Meta-analysis, effect size, fixed-effects models, random-effects models, mixed-effects models.

\section{RESUMEN}

El meta-análisis es una metodología de investigación que pretende integrar cuantitativamente los resultados de un conjunto de estudios empíricos sobre un determinado problema. Con este propósito, se calculan índices del tamaño del efecto y se codifican las características de los estudios con objeto de examinar su relación con los tamaños del efecto. El análisis estadístico en meta-análisis requiere ponderar cada estimación del efecto en función de su precisión asumiendo un modelo de efectos fijos o de efectos aleatorios. En este trabajo se presentan las etapas necesarias para realizar un metaanálisis, los diferentes modelos estadísticos que pueden asumirse y las consecuencias de asumir dichos modelos en la interpretación de sus resultados. Finalmente, los análisis estadísticos se ilustran con datos de un ejemplo real.

Palabras clave: Meta-análisis, tamaño del efecto, modelos de efectos fijos, modelos de efectos aleatorios, modelos de efectos mix tos.

Article received/Artículo recibido: December 15, 2009/Diciembre 15, 2009, Article accepted/Artículo aceptado: March 15, 2010/Marzo 15/2010

Dirección correspondencia/Mail Address:

Julio Sánchez-Meca, Dpto. Psicología Básica y Metodología, Facultad de Psicología, Campus de Espinardo, Universidad de Murcia, 30100-Murcia, Spain, E-mail: jsmeca@ um.es Fulgencio Marín-Martínez, University of Murcia, Spain

INTERNATIONAL JOURNAL OF PSYCHOLOGICAL RESEARCH esta incluida en PSERINFO, CENTRO DE INFORMACION PSICOLOGICA DE COLOMBIA, OPEN JOURNAL SYSTEM, BIBLIOTECA VIRTUAL DE PSICOLOGIA (ULAPSY-BIREME), DIALNET y GOOGLE SCHOLARS. Algunos de sus articulos aparecen en SOCIAL SCIENCE RESEARCH NETWORK y está en proceso de inclusion en diversas fuentes y bases de datos internacionales.

INTERNATIONAL JOURNAL OF PSYCHOLOGICAL RESEARCH is included in PSERINFO, CENTRO DE INFORMACIÓN PSICOLÓGICA DE COLOMBIA, OPEN JOURNAL SYSTEM, BIBLIOTECA VIRTUAL DE PSICOLOGIA (ULAPSY-BIREME), DIALNET and GOOGLE SCHOLARS. Some of its articles are in SOCIAL SCIENCE RESEARCH NETWORK, and it is in the process of inclusion in a variety of sources and international databases. 
International Journal of Psychological Research, 2010. Vol. 3. No. 1.

ISSN impresa (printed) 2011-2084

ISSN electrónica (electronic) 2011-2079

\section{Meta-analysis in Psychological Research}

\section{Introduction}

In the last 30 years meta-analysis has become a very useful methodological tool for accumulating research on a given topic. The huge growth of research in psychology has made it very difficult to synthesize the results in any field without the help of statistical methods to summarize the evidence. Unlike traditional reviews on a given topic, which are essentially subjective in nature, meta-analysis aims to imbue the research review with the same scientific rigor that is demanded of empirical studies: objectivity, systematization and replicability. Thus, metaanalysis is a method used to quantitatively integrate the results of a set of empirical studies on a given research question. With this purpose, the results of each individual study included in a meta-analysis have to be quantified in the same metric, usually by calculating an effect-size index, and then the effect estimates are statistically analyzed in order to: (a) obtain an average estimate of the effect magnitude, (b) assess heterogeneity among the effect estimates, and (c) search for characteristics of the studies that can explain the heterogeneity (Cooper, 2010; Cooper, Hedges, \& Valentine, 2009; Hunter \& Schmidt, 2004; Lipsey \& Wilson, 2001; Petticrew \& Roberts, 2006).

As meta-analysis aims to integrate single studies, the analysis unit is not the participant, but the single study. Therefore, the sample size in a meta-analysis is the number of studies that it has been possible to recover regarding the research question.

Meta-analysis is being applied in many different fields in psychology, but especially in evaluating the effectiveness of treatments, interventions, and prevention programs in such settings as mental health, education, social services, or human resources. Other psychological fields where meta-analysis is also being applied include areas such as gender differences in childhood, adolescence or with adults of many aptitudes and attitudes; psychometric validity of employment tests, and reliability generalization of psychological tests in general (Cook, Cooper, Cordray et al., 1992). Nowadays, it is very common to find meta-analytic studies on very different topics in any scientific psychology journal. Therefore, clinicians and researchers should have a sufficient knowledge base for correctly interpreting and/or carrying out meta-analyses.

This article is divided into four sections. Firstly, the phases in which a meta-analysis is carried out are presented. Then we outline the main statistical methods in meta-analysis. In the next section statistical methods for meta-analysis are illustrated using a real example. Finally, we present some concluding remarks.

International Journal of Psychological Research
Sánchez-Meca, J., Marín-Martínez, F., (2010). Meta-analysis in Psychological Research. International Journal of Psychological Research, 3 (1), 150-162.

\section{Phases in a Meta-analysis}

A meta-analysis is a scientific investigation and, consequently, it involves carrying out the same phases as in an empirical study. However, some of the phases have a few specificities that it is necessary to mention. Basically, we can conduct a meta-analysis in six phases: (1) Defining the research question; (2) literature search; (3) coding of studies; (4) calculating an effect-size index; (5) statistical analysis and interpretation, and (6) publication (Cooper, 2010; Egger, Davey Smith, \& Altman, 2001; Lipsey \& Wilson, 2001; Littell, Corcoran, \& Pillai, 2008; SánchezMeca \& Marín-Martínez, 2010.

(1) Defining the research question. As in any empirical study, the first step in a meta-analysis is to define the research question as clearly and objectively as possible. This implies proposing conceptual and operational definitions of the different concepts and constructs related to the research question. For example, in a meta-analysis about the efficacy of psychological treatments of obsessivecompulsive disorder (OCD), constructs such as psychological treatment, obsessive-compulsive disorder, and the measurement tools to assess efficacy were defined in this phase (Rosa-Alcázar, Sánchez-Meca, GómezConesa, \& Marín-Martínez, 2008).

(2) Literature search. Once the research question is formulated, the next step consists of defining the eligibility criteria of the single studies, that is, the characteristics a study must fulfill in order to be included in the meta-analysis. The selection criteria will depend on the purpose of the meta-analysis, but it is always necessary to specify the types of study designs that will be accepted (e.g., only experimental designs, or also quasi-experimental ones, etc.). For example, in the meta-analysis on OCD (Rosa-Alcázar et al., 2008) in order to be included in the meta-analysis the studies had to fulfill several criteria: (a) to apply a psychological treatment to adult patients with OCD; (b) to include a control group with OCD patients; (c) to report statistical data for calculating the effect sizes; (d) to have at least 5 participants in each group, and (e) to be published between 1980 and 2006.

In this phase the different strategies used to locate the single studies are also specified. No meta-analysis is complete without a search of electronic databases specifying the keywords used (e.g., PsycInfo, MedLine, ERIC). This search strategy is usually complemented by carrying out searches by hand of relevant journals and books for the topic of interest, and by checking the references of the papers included in the meta-analysis. Additionally, it is very advisable to try to locate unpublished papers that might fulfill the selection criteria, in order to counteract publication bias. This can be done by 
International Journal of Psychological Research, 2010. Vol. 3. No. 1.

ISSN impresa (printed) 2011-2084

ISSN electrónica (electronic) 2011-2079

sending letters to well-known researchers in the field requesting unpublished papers about the topic.

(3) Coding of studies. Once we have the single studies included in the meta-analysis, the next step is to record the main characteristics of the studies in order to later explain the heterogeneity exhibited by the effect sizes. The characteristics of the studies, or moderator variables, are classified as substantive, methodological, and extrinsic variables. Substantive characteristics are those related to the research question of the meta-analysis, whereas methodological variables are characteristics related to the study design. Finally, extrinsic variables refer to those characteristics that, despite are not related with the subjects nor the study design, could also have an influence in the results. In the OCD example (Rosa-Alcázar et al., 2008), substantive characteristics coded in the studies included the type of psychological treatment (e.g., cognitive therapy, exposure techniques), the mean age of the participants and the illness history (in years). Some of the methodological characteristics coded included the type of design (experimental versus quasi-experimental), attrition in the posttest, and the sample size. Moreover, extrinsic variables such as the country where the study was carried out and the education profile of the main author were also coded.

The coding norms of the moderator variables are written in a codebook. Some study characteristics are difficult to code due to incomplete or ambiguous reporting in the single studies. Therefore, the reliability of the coding process should be analyzed. To this end, two (or more) researchers should independently apply the codebook to all or a sample of the single studies. Then, using the coding records made by the researchers, agreement indices are applied (e.g., kappa coefficients, intraclass correlations) in order to assess the reliability of the coding process.

(4) Calculating an effect-size index. In the coding process of single studies, an effect-size index also has to be calculated in order to quantify the results of each study in a common metric. Depending on the study design and the type of dependent variables (continuous, dichotomous), different effect-size indices can be applied. Thus, when the studies have a two-group design and the outcome measure is continuous, the most appropriate effect-size index is the standardized mean difference or $d$. This is defined as the difference between the two means divided by a pooled within-study standard deviation. Furthermore, when the dependent variable is dichotomous, several risk indices can be applied: (a) the risk difference, $r d$, defined as the difference between the failure (or success) proportions for the two groups; (b) the risk ratio, $r r$, defined as the ratio between the two proportions, and (c) the odds ratio, or, defined as the ratio between the odds of the two groups. Finally, when the study applied a correlational design, a correlation coefficient can be used as the effect-size index
Sánchez-Meca, J., Marín-Martínez, F., (2010). Meta-analysis in Psychological Research. International Journal of Psychological Research, 3 (1), 150-162.

(e.g., the Pearson correlation coefficient, its Fisherô $Z$ transformation, the point-biserial correlation coefficient, the phi coefficient, etc.). Table 1 presents some of the usual effect-size indices applied in meta-analysis together with their estimated sampling variances, $\breve{\mathbb{F}}_{1}^{2}$, as they are used in the statistical analyses of a meta-analysis (cf. Borenstein, Hedges, Higgins, \& Rothstein, 2009; Cooper et al., 2009).

Once the effect-size index most appropriate to the characteristics of the studies has been selected, it is applied to each single study and its sampling variance is also calculated with the corresponding formulas (cf., e.g., Borenstein et al., 2009). When a meta-analysis includes studies with different designs (e.g., correlational and twogroup designs), there are formulas to transform different effect-size indices into each other. For example, it is possible to transform correlation coefficients into $d$ indices, and vice versa; or odds ratios into $d$ indices (Sánchez-Meca, Marín-Martínez, \& Chacón-Moscoso, 2003).

(5) Statistical analysis and interpretation. The dataset in a meta-analysis is composed of a matrix where the rows are the studies and the columns are the moderator variables, the effect-size index calculated in each study, and its sampling variance. With these data it is possible to carry out statistical analyses, which have the following three main objectives: (1) to calculate an average effect size and its confidence interval; (b) to assess the heterogeneity of the effect sizes around the average, and (c) to search for moderator variables that can explain the heterogeneity (Sutton \& Higgins, 2008). The main characteristic of metaanalysis is that statistical methods are used for integrating the study results. More details about how to statistically analyze a meta-analytic database are presented in the next point of this article.

(6) Publication. Finally, the results of a metaanalysis have to be published following the same structure as any other scientific paper: Introduction, method, results, and discussion and conclusions (Botella \& Gambara, 2006; Rosenthal, 1995). A literature review on the topic is outlined in the introduction, together with definitions of the constructs and variables implied in the research question, and the objectives and hypotheses of the meta-analysis. In the method section the following should be included: the selection criteria of the studies, the search strategy of the studies, the coding process of the study characteristics, the effect-size index calculated in the single studies, and the statistical analyses that were carried out in the metaanalytic integration. In the results section the characteristics of the studies are presented, together with the effect-size distribution, the mean effect size, the heterogeneity assessment, and the results of the statistical analyses for searching for moderator variables related to the effect sizes. Finally, in the discussion and conclusion section the results 
International Journal of Psychological Research, 2010. Vol. 3. No. 1.

ISSN impresa (printed) 2011-2084

ISSN electrónica (electronic) 2011-2079

of the meta-analysis are compared with previous ones, the implications for future research are mentioned, and the
Sánchez-Meca, J., Marín-Martínez, F., (2010). Meta-analysis in Psychological Research. International Journal of Psychological Research, 3 (1), 150-162.

limitations and the main conclusions of the meta-analysis are also outlined.

Table 1. Effect-size indices and their respective estimated within-study sampling variances

\begin{tabular}{|c|c|c|}
\hline Effect-size index & $T_{\mathrm{i}}$ & Estimated sampling variance, $\breve{\mathbb{f}}_{1}^{2}$ \\
\hline Mean difference & $D=\bar{y}_{E}-\bar{y}_{C}$ & $V(D)=\frac{S_{E}^{2}}{n_{E}}+\frac{S_{C}^{2}}{n_{C}}$ \\
\hline $\begin{array}{l}\text { Standardized mean } \\
\text { difference }\end{array}$ & $d=\left(1-\frac{3}{4 N-9}\right) \frac{\bar{y}_{E}-\bar{y}_{C}}{S}$ & $V(d)=\frac{n_{E}+n_{C}}{n_{E} n_{C}}+\frac{d^{2}}{2\left(n_{E}+n_{C}\right)}$ \\
\hline Risk difference & $r d=p_{E}-p_{C}$ & $V(r d)=\frac{p_{E}\left(1-p_{E}\right)}{n_{E}}+\frac{p_{C}\left(1-p_{C}\right)}{n_{C}}$ \\
\hline $\begin{array}{c}\text { Natural logarithm of the } \\
\text { risk ratio }\end{array}$ & $\operatorname{Lrr}=\log _{e}\left(p_{E} / p_{C}\right)$ & $V(L r r)=\frac{1-p_{E}}{n_{E} p_{E}}+\frac{1-p_{C}}{n_{C} p_{C}}$ \\
\hline $\begin{array}{l}\text { Natural logarithm of the } \\
\text { odds ratio) }\end{array}$ & $\operatorname{Lor}=\log _{e}\left[\frac{p_{E}\left(1-p_{C}\right)}{p_{C}\left(1-p_{E}\right)}\right]$ & $V($ Lor $)=\frac{1}{a}+\frac{1}{b}+\frac{1}{c}+\frac{1}{d}$ \\
\hline $\begin{array}{l}\text { Pearson correlation } \\
\text { coefficient }\end{array}$ & $r_{\mathrm{xy}}$ & $V\left(r_{x y}\right)=\frac{\left(1-r_{x y}^{2}\right)^{2}}{N-2}$ \\
\hline Fisherô $Z$ & $Z_{r}=\log _{e}\left(\frac{1+r_{x y}}{1-r_{x y}}\right)$ & $V\left(Z_{r}\right)=\frac{1}{N-3}$ \\
\hline
\end{tabular}

$\bar{y}_{E}$ and $\bar{y}_{C}$ : means for experimental and control groups. $S_{E}^{2}$ and $S_{C}^{2}$ : variances for experimental and control groups. $n_{\mathrm{E}}$ and $n_{\mathrm{C}}$ : sample sizes for experimental and control groups. $S$ : pooled standard deviation of the two groups. $N=n_{\mathrm{E}}$ $+n_{\mathrm{C}} \cdot p_{\mathrm{E}}$ and $p_{\mathrm{C}}$ : success (or failure) proportions for experimental and control groups. $a, b, c$, and $d$ : cell frequencies of success and failure for experimental and control groups.

\section{Statistical Methods in Meta-analysis}

The main characteristic of meta-analysis is the use of statistical methods to integrate the study results. In order to do this, an effect size estimate is calculated from each single study as well as a set of moderator variables (substantive and methodological characteristics) that can explain the variability in the effect size distribution. The statistical analysis in a meta-analysis proceeds in three steps (Lipsey \& Wilson, 2001): (1) the obtaining of an average effect size and a confidence interval around it; (2) the assessment of the heterogeneity of the effect sizes, and (3) if there is a large heterogeneity, the search for moderator variables that may be related to the effect sizes.

The effect sizes obtained from the single studies differ among themselves in terms of their precision, as they are calculated from different sample sizes. Effect sizes obtained from large samples are more accurate than those International Journal of Psychological Research obtained from small ones. As a consequence, statistical methods in meta-analysis take into account the accuracy of each effect size by weighting them as a function of its precision (Marín-Martínez \& Sánchez-Meca, in press; Sánchez-Meca \& Marín-Martínez, 1998). In particular, statistical theory shows that the most appropriate method (in terms of the minimum variance estimate) for weighting effect sizes in a meta-analysis involves using the inverse variance of each effect size estimate as the weighting factor (Cooper et al., 2009; Hedges \& Olkin, 1985).

(1) Averaging effect sizes. The first step in the statistical analyses consists in calculating an average effect size that summarizes the overall effect magnitude of the meta-analyzed studies. The statistical model for carrying out these calculations assumes a random-effects model, which considers that the effect size, $T_{\mathrm{i}}$, in each single study is estimating a different population effect size, $\Upsilon_{i}$, that is, $T_{i}$ $=\mathrm{d}_{\mathrm{i}}+u_{\mathrm{i}}$, where $u_{\mathrm{i}}$ represents the sampling error in $T_{\mathrm{i}}$ due to 
International Journal of Psychological Research, 2010. Vol. 3. No. 1.

ISSN impresa (printed) 2011-2084

ISSN electrónica (electronic) 2011-2079

the fact that the single study is based on a random sample selected from the population of potential participants (Field, 2003; Hedges \& Vevea, 1998; Schmidt, Oh, \& Hayes, 2009). The sampling error is quantified through the withinstudy sampling variance, $\stackrel{\circ}{\mathrm{i}}_{\mathrm{i}}^{2}$. Thus, it is assumed that in a given meta-analysis the included studies constitute a random sample of the studies which could have been carried out about the same topic. Moreover, for the included studies it is almost sure that the research conditions differ someway (e.g., in the therapistôs experience, the treatmentôs design and length, etc.), so it is reasonable to suspect that the effect sizes could vary owing to these differences. Thus, a distribution of population effect sizes, $\sigma_{i}$, with a mean population effect size, $\mu_{c}$ is assumed, that is, $\sigma_{i}=\mu_{d}+\stackrel{\circ}{\text {, }}$, with $\cup^{\circ}$ being the deviations of the population effect sizes from its mean. The variability of the population effect sizes is called the between-studies variance, $\tau^{2}$, or heterogeneity variance. Hence, in a random-effects model it is assumed that each effect size estimate includes two variability sources: the within-study variance, $\stackrel{\circ}{\mathrm{u}}_{\mathrm{i}}^{2}$, and the betweenstudies variance, $\tau^{2}$. The statistical model can be formulated as:

$$
T_{\mathrm{i}}=\mu_{\mathrm{a}}+\stackrel{\circ}{\mathrm{H}}+u_{\mathrm{i}}
$$

When $\cup^{\circ}=0$, then the random-effects model becomes a fixed-effects model, where there is only one variability source, the within-study variance $\stackrel{\mathrm{u}}{\mathrm{i}}_{\mathrm{i}}^{2}$, and all of the studies are estimating the same population effect size. Thus, the statistical model is simplified to $T_{\mathrm{i}}=\mu_{\mathrm{d}}+u_{\mathrm{i}}$, and $\mu_{\mathrm{d}}=\mathrm{d}_{\mathrm{s}}$.

In practice the meta-analyst will have to decide which statistical model to apply, the fixed- or the randomeffects model. The consequences of assuming a randomeffects model or a fixed-effects one concern the interpretation of the results and also the results obtained themselves. On the one hand, a meta-analyst that applies a fixed-effects model is assuming that his/her results can only be generalized to an identical population of studies to that of the individual studies included in the meta-analysis, whereas in a random-effects model the results can be generalized to a wider population of studies. On the other hand, the error attributed to the effect size estimates in a fixed-effects model is smaller than in a random-effects model, which is why in the first model the confidence intervals are narrower and the statistical tests more liberal than in the second one. The main consequence of assuming a fixed-effects model when the meta-analytic data come from a random-effects model is that we may attribute more precision to the effect size estimates than is really appropriate and that we may find statistically significant relationships between variables that are actually spurious.
Sánchez-Meca, J., Marín-Martínez, F., (2010). Meta-analysis in Psychological Research. International Journal of Psychological Research, 3 (1), 150-162.

Consequently, it is more realistic to assume random-effects models in meta-analysis.

In order to apply statistical inference, it is usually assumed that the effect size distribution, $T_{\mathrm{i}}$, in a randomeffects model follows a normal distribution with population mean $\mu_{d}$ and variance equal to the sum of the two variability sources, $\stackrel{\circ}{\mathrm{i}}_{\mathrm{i}}^{2}+\tau^{2}$, that is, $T_{\mathrm{i}} \sim N\left(\mu_{\alpha} ; \stackrel{\circ}{\mathrm{u}}_{\mathrm{i}}^{2}+\tau^{2}\right)$.

Thus, the uniformly minimum variance unbiased estimator of $\mu_{\mathrm{o}} \bar{T}_{\mathrm{U}}$, is given by (Viechtbauer, 2005):

$$
\bar{T}_{\mathrm{U}}=\frac{\sum_{i} w_{i} T_{i}}{\sum_{i} w_{i}},
$$

where $w_{\mathrm{i}}$ are the optimal weights, defined as $w_{\mathrm{i}}=1 /\left(\stackrel{\circ}{\mathrm{u}}_{\mathrm{i}}^{2}+\stackrel{\mathrm{U}}{\mathrm{f}}\right)$. The variance of $\bar{T}_{\mathrm{U}}$ is given by:

$$
V\left(\bar{T}_{\mathrm{U}}\right)=\frac{1}{\sum_{i} w_{i}}
$$

However, in practice the optimal weights cannot be calculated, because the parametric within-study variances, $\stackrel{\circ}{\mathrm{u}}_{\mathrm{i}}^{2}$, and the parametric between-studies variance, $\tau^{2}$, are unknown. Therefore, the two kinds of variance have to be estimated from the data. In general, good estimators of the within-study variance for the different effect-size indices have been proposed in the meta-analytic literature (cf. e.g., Borenstein et al., 2009). About a dozen different estimators have been proposed for estimating the between-studies variance (Sánchez-Meca \& Marín-Martínez, 2008; Viechtbauer, 2005). Of these, the most usually applied are those based on the moments method, 菒, proposed by DerSimonian and Laird (1986), and the one based on restricted maximum likelihood, 首 estimator is given by:

$$
\text { 兑 }=\frac{Q-(k-1)}{c} \text {, }
$$

where $k$ is the number of studies in the metaanalysis; $Q$ is the heterogeneity statistic defined as:

$$
Q=\sum_{i} \tilde{w}_{i}\left(T_{i}-\overline{\tilde{T}}\right)^{2},
$$


International Journal of Psychological Research, 2010. Vol. 3. No. 1.

ISSN impresa (printed) 2011-2084

ISSN electrónica (electronic) 2011-2079

with $\tilde{w}_{\mathrm{i}}=1 / \widetilde{\mathbb{F}}_{1}^{2}$ being the estimated weights by assuming a fixed-effects model, and $\overline{\widetilde{T}}$ being the average effect size also by assuming a fixed-effects model, that is: $\overline{\tilde{T}}=\sum_{i} \tilde{w}_{i} T_{i} / \sum_{i} \tilde{w}_{i}$. Finally, in equation (4), $c$ is obtained by:

$$
c=\sum_{i} \tilde{w}_{i}-\frac{\sum_{i}\left(\tilde{w}_{i}\right)^{2}}{\sum_{i} \tilde{w}_{i}} .
$$

In Equation (4), when $Q<(k \ddot{i} 1)$, then Q $_{\mathrm{L}}$ is truncated to 0 to avoid negative values.

The between-studies variance estimator based on restricted maximum likelihood, 每EML, is obtained by iterating until convergence the equation (Thompson \& Sharp, 1999):

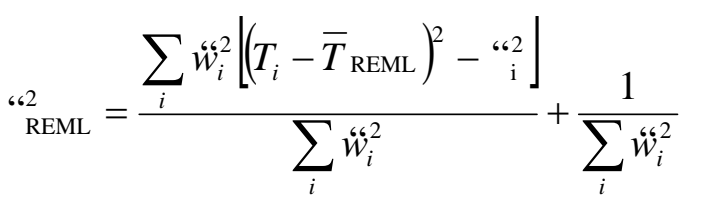

with $\breve{\mathbb{F}_{1}}=1 /\left(\breve{\mathbb{F}}_{1}^{2}+\ddot{\theta}\right)$, where $\ddot{\theta}$ is initially 0 or it is estimated by any of the noniterative estimators of the between-studies variance (e.g., 菒L $)$ and $\bar{T}_{\text {REML }}$ is given by:

$$
\bar{T}_{\mathrm{REML}}=\frac{\sum_{i} \sqrt[\breve{\mathrm{E}}_{i}]{T_{i}}}{\sum_{i} \sqrt{\overline{\mathbb{F}}_{l}}}
$$

In each iteration of Equations (7) and (8), each estimate of $\tau^{2}$ must be checked in order to avoid negative values.

Once we have an estimate of the between-studies variance ( E $_{\mathrm{DL}}$ or 㒸EML ) and the effect estimates, $T_{\mathrm{i}}$, and their estimated within-study variances, $\widetilde{\mathbb{F}_{1}^{2}}$, it is possible to calculate an average effect size by:

$$
\bar{T}=\frac{\sum_{i} \breve{\sqrt{2}}_{i} T_{i}}{\sum_{i} \breve{\mathrm{F}}_{i}}
$$

(9) with

$\breve{\sqrt{\sqrt{1}}}=1 /\left(\breve{\mathbb{F}}_{1}^{2}+\breve{G}\right)$. Then a confidence interval for $\bar{T}$ is usually calculated by assuming a normal distribution:

International Journal of Psychological Research
Sánchez-Meca, J., Marín-Martínez, F., (2010). Meta-analysis in Psychological Research. International Journal of Psychological Research, 3 (1), 150-162.

$$
\bar{T} \pm\left|z_{\alpha / 2}\right| \sqrt{V(\bar{T})}
$$

where $z_{\breve{Y} 2}$ is the $100(\breve{U} / 2)$ percentile of the standard normal distribution, Ŭ being the significance level; and $V(\bar{T})$ is the sampling variance of the average effect size, which is obtained by:

$$
V(\bar{T})=\frac{1}{\sum_{i} \sqrt[\overline{\mathbb{E}}_{l}]{ }}
$$

Although Equation (10) is the usual procedure for calculating a confidence interval around the overall effect size, this method does not take into account the uncertainty produced by the fact that the within-study and the betweenstudies variances have to be estimated. As a consequence, the confidence interval will underestimate the nominal confidence level. A confidence interval that better fits the nominal confidence level is that proposed by Hartung (1999; see also Sánchez-Meca \& Marín-Martínez, 2008; Sidik \& Jonkman, 2003, 2006), which assumes a Student $t$ distribution with $k \ddot{i} 1$ degrees of freedom and estimates the sampling variance of the overall effect size by an improved formula:

$$
\bar{T} \pm\left|t_{k-1, \alpha / 2}\right| \sqrt{V_{\mathrm{W}}(\bar{T})}
$$

where $V_{\mathrm{W}}(\bar{T})$ is the improved sampling variance estimate and is given by:

$$
V_{\mathrm{W}}(\bar{T})=\frac{\sum_{i} \overline{\mathbb{E}}_{i}\left(T_{i}-\bar{T}\right)^{2}}{(k-1) \sum_{i} \overline{\sqrt{\mathbb{F}_{l}}}} .
$$

Finally, together with the average effect size and its confidence interval, it is very informative to present a graph that was specially developed for meta-analysis named óforest plotô A forest plot is a graphical presentation of each effect size estimate with its confidence interval and the overall effect size also with its confidence interval. Thus, a forest plot is something like a photograph of the effect estimates obtained in the meta-analysis (Borenstein et al., 2009; Higgins \& Green, 2008).

(2) Assessing heterogeneity. Whilst it is important in meta-analysis to obtain an overall effect size, it is even more important to assess the heterogeneity of the effect estimates around its mean. We need to know whether the variability in the effect sizes is due only to sampling error or if there is more variability than can be explained by sampling error. This question is usually answered by 
International Journal of Psychological Research, 2010. Vol. 3. No. 1.

ISSN impresa (printed) 2011-2084

ISSN electrónica (electronic) 2011-2079

applying the heterogeneity $Q$ statistic, which was defined in Equation (5). Under the null hypothesis of heterogeneity due only to sampling error, the $Q$ statistic follows a Chisquare distribution with $k \ddot{i} 1$ degrees of freedom. Thus, by comparing $Q$ with the $100(1 \quad \ddot{i} \quad \breve{U})$ percentile of $\chi_{k-1}^{2}$ distribution, it is possible to make a statistical decision about this question.

When a meta-analysis has a small number of studies, the $Q$ statistic has low statistical power (Harwell, 1997; Sánchez-Meca \& Marín-Martínez, 1997). Thus, it is usual to assess heterogeneity by complementing the $Q$ statistic with the $I^{2}$ index, a percentage that informs us about the extent of variability in the effect size distribution due to true heterogeneity (that is, heterogeneity not due to sampling error, but to the influence of many different moderator variables). The $I^{2}$ index is calculated by (Higgins \& Thompson, 2002):

$$
I^{2}=\frac{Q-(k-1)}{Q} \times 100
$$

When $Q<(k i \mathrm{i} 1)$ then $I^{2}$ is truncated to 0 . Higgins and Thompson (2002) proposed a tentative classification of $I^{2}$ by stating that $I^{2}$ values around $25 \%, 50 \%$, and $75 \%$ can be considered as reflecting small, medium, and large heterogeneity, respectively.

(3) Searching for moderator variables. When the $Q$ statistic achieves a statistically significant result and the $I^{2}$ index is of medium to large magnitude, then the overall effect size calculated in the first step of the statistical analyses does not adequately represent all of the study results. As a consequence, the next step in the analyses consists in searching for moderator variables that can explain the heterogeneity. In this phase of the analysis, the effect estimates, $T_{\mathrm{i}}$, act as the dependent variable, whereas the moderator variables are potential predictors that may be related to the effect estimates. Depending on the categorical or continuous nature of the moderator variables, analyses of variance (ANOVAs) or regression analyses are applied in order to examine the influence of these predictors on the effect magnitude. In all cases, however, weighting methods are applied that take into account the precision of the effect estimates. In particular, the most appropriate statistical model for testing the influence of moderator variables in meta-analysis is to assume a mixed-effects model, where the moderator variable is the fixed-effects component and the studies are the random-effects component in the model (Konstantopoulos \& Hedges, 2009; Raudenbush, 2009).

For categorical moderator variables, ANOVAs are applied by weighted least squares estimation. An ANOVA for testing the significance of a categorical moderator
Sánchez-Meca, J., Marín-Martínez, F., (2010). Meta-analysis in Psychological Research. International Journal of Psychological Research, 3 (1), 150-162.

variable with $m$ categories consists of calculating a weighted average effect size for each category, $\bar{T}_{\mathrm{j}}$, and obtaining the $Q_{\mathrm{B}}$ statistic by:

$$
Q_{\mathrm{B}}=\sum_{j}^{m} \breve{\underline{k}}_{\mathrm{j}}\left(\bar{T}_{\mathrm{j}}-\bar{T}\right)^{2}
$$

with $\quad \breve{\sqrt{\mathrm{j}}}_{\mathrm{j}}=1 / V\left(\bar{T}_{\mathrm{j}}\right)$, and $V\left(\bar{T}_{\mathrm{j}}\right)=1 / \sum_{i}^{m_{j}} \breve{\sqrt{\mathrm{i}}}_{\mathrm{j}}$. The $Q_{\mathrm{B}}$ statistic is the weighted between-categories sum of squares of the ANOVA. Under the null hypothesis of no difference between the mean effect sizes for the $m$ categories ( $H_{0}: \varepsilon_{\mathrm{d}_{1}}=\ldots=\varepsilon_{\mathrm{d}_{\mathrm{m}}}$ ), the $Q_{\mathrm{B}}$ statistic follows a Chisquare distribution with $m$ ï 1 degrees of freedom. Thus, from comparing the $Q_{\mathrm{B}}$ statistic with the $100\left(\begin{array}{lll}1 & \ddot{\mathrm{I}} & \breve{4}\end{array}\right)$ percentile of $\chi_{m-1}^{2}$ distribution, it is possible to decide whether the moderator variable is statistically related to the effect size.

The result of $Q_{\mathrm{B}}$ is complemented with a misspecification test that can be applied separately for each category of the moderator variable. Thus, the $Q_{\mathrm{W}_{\mathrm{j}}}$ statistic for the $j$ th category is obtained by:

$$
Q_{\mathrm{w}_{\mathrm{j}}}=\sum_{i}^{m_{j}} \breve{\mathrm{F}}_{\mathrm{ij}}\left(T_{\mathrm{ij}}-\bar{T}_{\mathrm{j}}\right)^{2}
$$

A different $Q_{\mathrm{W}_{\mathrm{j}}}$ statistic is calculated for each category of the moderator variable in order to examine the heterogeneity of the effect sizes within a given category. Thus, under the null hypothesis of homogeneous effect sizes in the $j$ th category, the $Q_{\mathrm{w}_{\mathrm{j}}}$ statistic follows a Chisquare distribution with $m_{\mathrm{j}} \mathrm{i} 1$ degrees of freedom, where $m_{\mathrm{j}}$ is the number of effect sizes in the $j$ th category. Therefore, by comparing $Q_{\mathrm{W}_{\mathrm{j}}}$ with the $100\left(\begin{array}{lll}1 & \ddot{\mathrm{I}} & \mathrm{U}\end{array}\right)$ percentile of $\chi_{m_{j}-1}^{2}$ distribution, it is possible to decide whether the effect sizes in the $j$ th category are homogeneous. In addition, a global misspecification test for all ANOVA model consists of calculating the sum of the $m$ $Q_{\mathrm{W}_{\mathrm{j}}}$ statistics as follows:

$$
Q_{W}=Q_{\mathrm{W}_{1}}+\ldots+Q_{\mathrm{w}_{\mathrm{m}}} .
$$

The $Q_{\mathrm{W}}$ statistic is the weighted within-categories sum of squares of the ANOVA. Thus, under the null hypothesis of global homogeneity for all categories, the $Q_{\mathrm{W}}$ statistic follows a Chi-square distribution with $k$ ï $m$ 
International Journal of Psychological Research, 2010. Vol. 3. No. 1.

ISSN impresa (printed) 2011-2084

ISSN electrónica (electronic) 2011-2079

degrees of freedom. By comparing $Q_{\mathrm{W}}$ with the $100(1 \mathrm{i}$ Ŭ) percentile of $\chi_{k-m}^{2}$ distribution, it is possible to decide whether the ANOVA model is globally misspecified.

When the moderator variable is continuous or we are interested in examining the influence of a set of moderator variables (continuous and/or categorical), weighted simple or multiple linear regression models can be applied. By assuming a mixed-effects model, where the moderator variables are the fixed-effects component and the studies the random-effects component, the linear model is given by:

$$
\mathbf{T}=\mathbf{X} \mathbf{6}+\mathbf{u}+\mathbf{C}^{\mathbf{c}}
$$

with $\mathbf{T}$ being a $k$ by 1 vector of effect size estimates with elements $\left\{T_{\mathrm{i}}\right\}, \mathbf{X}$ is a $k$ by $P$ matrix of predictors, with $P=p+1$ columns ( $p$ being the number of predictors), $\mathbf{6}$ is a $P$ by 1 vector of parametric regression coefficients with elements $\left\{\boldsymbol{\sigma}_{\mathrm{j}}\right\}$, $\mathbf{u}$ is a $k$ by 1 vector of within-study estimation errors with elements $\left\{u_{\mathrm{i}}\right\}$, and $\mathbf{U}$ is a scalar with the between-studies variance $\left\{\dot{U}^{\circ}\right.$. T has variance $V\left(\mathbf{u}+\mathbf{U}=\tau^{2} \mathbf{I}+\mathbf{V}\right.$, with $\mathbf{I}$ being a $k$ by $k$ identity matrix and $\mathbf{V}$ being a $k$ by $k$ diagonal matrix with elements $\left\{v_{\mathrm{i}}=\stackrel{\circ}{\mathrm{u}}_{\mathrm{i}}^{2}+\mathrm{U}^{\prime}\right\}$.

The vector of regression coefficients, $\mathbf{6}$, is estimated by:

$$
\breve{\overline{\mathbf{b}}}=\left(\mathbf{X}^{\prime} \mathbf{W X}\right)^{-1} \mathbf{X}^{\prime} \mathbf{W} \mathbf{T},
$$

with $\mathbf{W}=\breve{\vec{F}}^{-1}$, W being a $k$ by $k$ diagonal matrix with the weights for each effect size, $\left\{\breve{V}_{1}\right\}$, which are estimated by the inverse of the sum of the within-study and the betweenstudies variances: $\overline{\sqrt{\mid}}=1 /\left(\breve{\mathbb{F}}_{1}^{2}+\breve{G}\right)$. In this case, the between-studies variance is estimated by an extension of Equations (4) or (7) to the case of a regression model with $p$ predictors. For example, an extension of the moments method estimator is given by:

$$
\ddot{\mathrm{Q}}_{\mathrm{MM}}=\frac{Q_{E}-(k-p-1)}{\operatorname{tr}(\mathbf{W})-\operatorname{tr}\left[\mathbf{W X}\left(\mathbf{X}^{\prime} \mathbf{W X}\right)^{-1} \mathbf{X}^{\prime} \mathbf{W}\right]} \text {, }
$$

where $Q_{\mathrm{E}}$ is the weighted residual sum of squares of the model and is obtained by:

$$
Q_{\mathrm{E}}=\mathbf{T}^{\prime} \mathbf{W} \mathbf{T}-Q_{\mathrm{R}}
$$

The between-studies variance estimator based on restricted maximum likelihood for a weighted regression model can be consulted in Thompson and Sharp (1999).

International Journal of Psychological Research
Sánchez-Meca, J., Marín-Martínez, F., (2010). Meta-analysis in Psychological Research. International Journal of Psychological Research, 3 (1), 150-162.

A test for the statistical significance of the full model is given by the $Q_{\mathrm{R}}$ statistic, which is the weighted regression sum of squares and is given by:

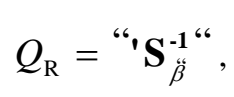

where $\mathbf{S}_{\breve{F}}$ is the matrix of variances and covariances for the regression coefficients. Under the null hypothesis of no relationship between the composite of predictors and the effect sizes $\left(\mathrm{H}_{0}: \quad \mathbf{6}=\mathbf{0}\right), Q_{\mathrm{R}}$ follows a Chi-square distribution with $P$ degrees of freedom. By comparing $Q_{\mathrm{R}}$ with the 100(1 $\ddot{i} \quad \check{U})$ percentile of $\chi_{P}^{2}$ distribution, it is possible to decide if the full model shows a statistically significant relationship with the effect size. At the same time, statistical tests for individual predictors can also be applied in order to examine the influence of each predictor once that of the other predictors in the model has been partialized. For a given regression coefficient, $\bar{\beta}_{\mathrm{j}}$, the null hypothesis of no effect is tested by:

$$
\mathrm{Z}=\frac{\check{\mathscr{G}}_{\mathrm{j}}}{\sqrt{V\left(\overline{F_{\mathrm{j}}}\right)}},
$$

with $V\left(\check{\beta}_{\mathrm{j}}\right)$ being the $j$ th diagonal element of the $P$ by $P$ matrix for the variances and covariances of the regression coefficients. Thus, comparing $|Z|$ with the $100(1$ $\ddot{i}$ Ü2) percentile of the standard normal distribution, it is possible to determine the statistical significance of a given predictor in the multiple regression model.

Finally, a specification test of the regression model is applied by means of the $Q_{\mathrm{E}}$ statistic defined in Equation (21). Under the null hypothesis that the model is well specified $\left(\mathrm{H}_{0}\right.$ : $\left.\quad \mathrm{U}_{\mathrm{WLS}}=0\right), Q_{\mathrm{E}}$ follows a Chi-square distribution with $k$ ï $p$ ï 1 degrees of freedom. Thus, by comparing $Q_{\mathrm{E}}$ with the $100(1 \quad \ddot{i} \quad \breve{U})$ percentile of $\chi_{k-p-1}^{2}$ distribution, it is possible to examine the model misspecification.

\section{An Illustrative Example}

In order to illustrate the calculations in a typical meta-analysis, Table 2 presents some of the data obtained in a meta-analysis on the efficacy of psychological treatments for obsessive-compulsive disorder (OCD; RosaAlcázar et al., 2008). This meta-analysis is composed of 24 studies that compared two groups of patients with OCD, one receiving a psychological treatment (experimental 
International Journal of Psychological Research, 2010. Vol. 3. No. 1.

ISSN impresa (printed) 2011-2084

ISSN electrónica (electronic) 2011-2079

group) and the other one not receiving treatment (control group). The effect-size index calculated in each study was the standardized mean difference, $d$, defined as the difference between the means for the treatment and control groups divided by a pooled estimate of the standard deviations for the two groups. Positive values for $d$ indicated a lower level of obsessions and compulsions after treatment in the treated group in comparison with the control group, whereas negative values for $d$ indicated a higher level. Table 2 also includes the sample sizes for the two groups ( $n_{\mathrm{E}}$ and $n_{\mathrm{C}}$ ), as well as the estimated withinstudy sampling variance for each effect size $\left(\widetilde{\mathbb{E}}_{1}^{2}\right)$.

Table 2. Dataset of the meta-analysis about the efficacy of psychological treatments for OCD.

\begin{tabular}{ccccccc}
\hline Study & Year & Design & $n_{\mathrm{Ei}}$ & $n_{\mathrm{Ci}}$ & $d_{\mathrm{i}}$ & $\breve{\mathbb{F}}_{1}^{2}$ \\
\hline 1 & 1998 & 1 & 10 & 8 & 1.425 & 0.2814 \\
2 & 2003 & 2 & 22 & 23 & 1.068 & 0.1016 \\
3 & 1993 & 2 & 29 & 32 & 0.924 & 0.0727 \\
4 & 1993 & 2 & 29 & 32 & 0.909 & 0.0725 \\
5 & 2005 & 1 & 3 & 11 & 0.281 & 0.1355 \\
6 & 2005 & 2 & 21 & 20 & 1.646 & 0.1307 \\
7 & 1997 & 2 & 15 & 14 & 1.007 & 0.1556 \\
8 & 2002 & 2 & 55 & 66 & 0.996 & 0.0374 \\
9 & 2002 & 2 & 55 & 66 & 0.731 & 0.0355 \\
10 & 1998 & 2 & 11 & 10 & 1.882 & 0.2752 \\
11 & 2000 & 2 & 13 & 16 & 1.082 & 0.1596 \\
12 & 1997 & 2 & 9 & 9 & 2.326 & 0.3725 \\
13 & 1994 & 2 & 6 & 6 & -0.229 & 0.3355 \\
14 & 1980 & 2 & 10 & 10 & 0.191 & 0.2009 \\
15 & 2001 & 2 & 18 & 33 & 0.980 & 0.0953 \\
16 & 2001 & 2 & 16 & 33 & 1.620 & 0.1196 \\
17 & 2005 & 2 & 10 & 8 & 2.997 & 0.4745 \\
18 & 1999 & 1 & 6 & 6 & 0.860 & 0.3642 \\
19 & 2006 & 2 & 10 & 10 & 1.494 & 0.2558 \\
20 & 2003 & 1 & 11 & 15 & 0.597 & 0.1644 \\
21 & 1998 & 2 & 19 & 16 & 0.674 & 0.1216 \\
22 & 1998 & 2 & 19 & 16 & 0.490 & 0.1186 \\
23 & 2004 & 2 & 6 & 9 & 3.780 & 0.7541 \\
24 & 2004 & 2 & 10 & 9 & 1.590 & 0.2776 \\
\hline & & & & & &
\end{tabular}

Design type: 1 , quasi-experimental; 2 , experimental. $n_{\mathrm{Ei}}$ and $n_{\mathrm{Ci}}$ are the sample sizes for the experimental and control groups, respectively. $d_{\mathrm{i}}$ is the standardized mean difference between the means for the experimental and control groups. $\breve{\mathbb{E}}_{1}^{2}$ is the estimated within-study sampling variance.
Sánchez-Meca, J., Marín-Martínez, F., (2010). Meta-analysis in Psychological Research. International Journal of Psychological Research, 3 (1), 150-162.

In the example, $d_{\mathrm{i}}$ values correspond to the term $T_{\mathrm{i}}$ used in the previous section to represent the effect estimates. The statistical analyses should begin with a forest plot to graphically represent the individual effect estimates and their confidence intervals, together with an average effect size. Figure 1 presents a forest plot for the example data.

Figure 1. Forest plot for the example data. The effect-size index is the standardized mean difference, $d$. The mean effect size was calculated by assuming a randomeffects model with $\mathrm{B}_{\mathrm{L}}$. The confidence interval for the mean effect size was calculated from the classical method.

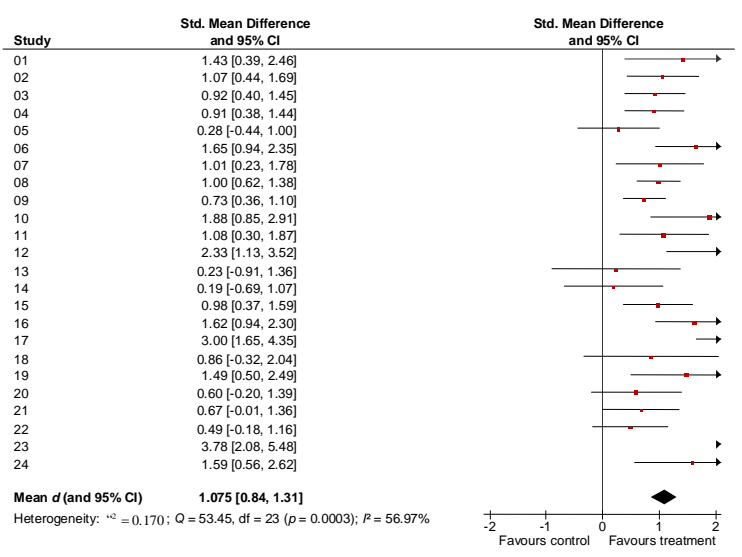

Once we have a general impression of the effect size distribution, the statistical analyses begin by calculating an average effect estimate. By assuming a random-effects model, this implies estimating the betweenstudies variance, $\tau^{2}$. In this paper we have presented two alternative estimators of $\tau^{2}$ : that based on the moments method, $\hat{\mathrm{Q}}_{\mathrm{L}}$, and that based on restricted maximum likelihood, 曾EML . By applying Equations (4) and (7) to the example data, we obtain 寃 $=0.170$ and 首 $=0.162$. For comparison purposes, Table 3 presents different average effect sizes and confidence intervals depending on the statistical model assumed (fixed- versus random-effects model), the between-studies variance estimator ( $\hat{\mathrm{Q}}_{\mathrm{L}}$ versus $\mathrm{B}_{\mathrm{REML}}$ ), and the confidence interval method (classical versus improved by Hartung, 1999). The weighted mean effect size that we obtained by applying Equation (9) was $\bar{d}=1.075$ when we used $\hat{\mathrm{Q}}_{\mathrm{L}}$ in the

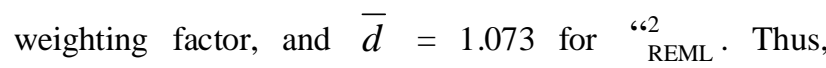
changing the between-studies variance estimator does not seem to affect the mean effect size estimate. Assuming a fixed-effects model the mean effect size is also similar to those obtained from a random-effects model: $\bar{d}=0.993$. 
Table 3. Summary statistics for the average effect size and its confidence interval calculated from different methods

\begin{tabular}{|c|c|c|c|c|c|}
\hline Statistical model & $\tau^{2}$ estimator & CI method & $\bar{d}$ & $\begin{array}{cc}95 \% & \text { C. I. } \\
d_{1} & d_{\mathrm{u}} \\
\end{array}$ & $\begin{array}{l}\text { Width } \\
\text { of the CI }\end{array}$ \\
\hline RE model & $\mathrm{E}_{\mathrm{L}}^{\mathrm{L}}=0.170$ & Classical & 1.075 & $0.843 \quad 1.306$ & 0.463 \\
\hline RE model & $\ddot{\mathrm{B}}_{\mathrm{B}}=0.170$ & Improved & 1.075 & $0.786 \quad 1.363$ & 0.577 \\
\hline RE model & 并 $_{\mathrm{RML}}=0.162$ & Classical & 1.073 & $0.844 \quad 1.302$ & 0.458 \\
\hline RE model & 㒸 $_{\mathrm{RML}}=0.162$ & Improved & 1.073 & $0.785 \quad 1.360$ & 0.572 \\
\hline FE model & -- & Classical & 0.993 & $0.852 \quad 1.134$ & 0.282 \\
\hline
\end{tabular}

RE: random-effects model. FE: fixed-effects model. CI: confidence interval. $\bar{d}$ : average effect size. $d_{1}$ and $d_{\mathrm{u}}$ : lower and upper confidence limits for the average effect size.

Following Cohenôs (1988) benchmarks for interpreting the practical significance of an effect size, we can consider that $d$ values around $0.20,0.50$, and 0.80 can be interpreted as reflecting an effect of small, medium, and large magnitude, respectively. Therefore, a mean effect size in our example of $\bar{d}=1.075$ can be interpreted as indicating a high effect of psychological treatments in reducing obsessions and compulsions of patients with OCD.

Table 3 also shows confidence intervals for the average effect size depending on the method selected (classical versus improved by Hartung, 1999) and on the between-studies variance estimator (moments method versus restricted maximum likelihood). With the classical method for calculating a confidence interval around the mean effect size the width of the confidence interval $(0.463$ and 0.458 for $\mathrm{Q}_{\mathrm{L}}$ and $\mathrm{E}_{\mathrm{REML}}$, respectively) was smaller

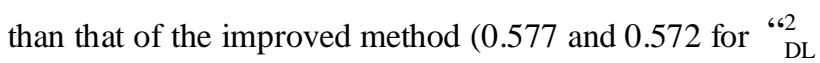

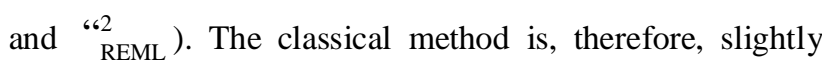
more liberal in comparison with the improved method. The most liberal method, however, is the confidence interval which assumes a fixed-effects model as it does not take into account the between-studies variability among the effect sizes.

Once we have an estimate of the overall effect magnitude in the meta-analysis, the next step in the analyses consists of assessing the heterogeneity of the effect sizes. By applying Equation (5) to our example data, we obtained $Q(23)=53.452, p=.0003$, which enabled us to reject the null hypothesis of homogenous effect sizes. The statistically significant result for the $Q$ statistic is complemented with the calculation of the $I^{2}$ index by Equation (14), reaching a moderate heterogeneity, $I^{2}=$ $56.97 \%$. Therefore, we can conclude that the effect sizes were clearly heterogeneous and, as a consequence, the next step in the analyses is to search for moderator variables which are able to explain the effect size variability.

International Journal of Psychological Research
In order to illustrate how to test different moderator variables on the effect sizes, here we have selected two of them: one categorical variable and the other continuous. As an example of a categorical moderator variable, we have selected the design type, distinguishing between experimental (random assignment to the groups) versus quasi-experimental designs (nonrandom assignment). For comparison purposes, Table 4 shows the weighted ANOVA results for the design type by assuming a mixed-effects model with two different estimators of the

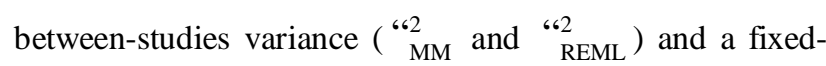
effects model. In the three cases we obtained, using Equation (15), a nonstatistically significant result for the $Q_{\mathrm{B}}$ statistic, leading to the conclusion that the type of design does not seem to affect the effect sizes, although quasiexperimental designs presented a mean effect size thatwas slightly lower than that of the experimental ones. Wecan also observe how the $Q_{\mathrm{B}}$ statistic for the fixed-effects model was the most liberal of the three models applied.

Table 4. Results of the weighted ANOVA applied on the design type by assuming a random-effects model

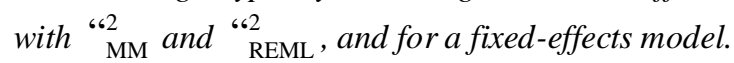

\begin{tabular}{|c|c|c|c|c|c|c|c|}
\hline \multicolumn{8}{|c|}{ Mixed-Effects Model with $\mathrm{Q}_{\mathrm{MM}}=0.168$} \\
\hline Design type & $k$ & $\bar{d}_{j}$ & $\frac{95 \%}{d_{1}}$ & $\frac{\text { C. I. }}{d_{\mathrm{u}}}$ & $Q_{\mathrm{Wj}_{\mathrm{j}}}$ & $\begin{array}{l}D \\
F\end{array}$ & $p$ \\
\hline Quasi-exptal & 4 & 0.721 & 0.114 & 1.329 & 1.822 & 3 & .610 \\
\hline Exptal & 20 & 1.134 & 0.884 & 1.384 & 29.069 & 19 & .065 \\
\hline $\begin{array}{l}\text { ANOVA } \\
\text { results }\end{array}$ & \multicolumn{7}{|c|}{$\begin{array}{l}Q_{\mathrm{B}}(1)=1.514, p=.218 \\
Q_{\mathrm{W}}(22)=30.891, p=.098\end{array}$} \\
\hline \multicolumn{8}{|c|}{ Mixed-Effects Model with Ğ $_{\mathrm{REML}}=0.113$} \\
\hline Design type & $k$ & $\bar{d}_{j}$ & $\frac{95 \%}{d_{1}}$ & $\frac{\text { C. I. }}{d_{\mathrm{u}}}$ & $Q_{\mathrm{Wj}}$ & $\begin{array}{l}D \\
F\end{array}$ & $p$ \\
\hline Quasi-exptal & 4 & 0.710 & 0.149 & 1.270 & 2.127 & 3 & .546 \\
\hline Exptal & 20 & 1.114 & 0.889 & 1.339 & 32.864 & 19 & .025 \\
\hline
\end{tabular}


International Journal of Psychological Research, 2010. Vol. 3. No. 1.

ISSN impresa (printed) 2011-2084

ISSN electrónica (electronic) 2011-2079

\begin{tabular}{|c|c|c|c|c|c|c|c|}
\hline $\begin{array}{l}\text { ANOVA } \\
\text { results }\end{array}$ & \multicolumn{4}{|c|}{$\begin{array}{l}Q_{\mathrm{B}}(1)=1.725, p=.189 \\
Q_{\mathrm{W}}(22)=34.991, p=.039\end{array}$} & & & \\
\hline \multicolumn{8}{|c|}{ Fixed-Effects Model } \\
\hline Design type & $k$ & $\bar{d}_{j}$ & $\frac{95 \%}{d_{1}}$ & $\frac{\text { C. I. }}{d_{\mathrm{u}}}$ & $Q_{\mathrm{Wj}}$ & $\begin{array}{l}D \\
F\end{array}$ & $p$ \\
\hline Quasi-exptal & 4 & 0.664 & 0.223 & 1.105 & 3.273 & 3 & .351 \\
\hline Exptal & 20 & 1.030 & 0.881 & 1.179 & 47.809 & 19 & .0003 \\
\hline $\begin{array}{l}\text { ANOVA } \\
\text { results }\end{array}$ & \multicolumn{7}{|c|}{$\begin{array}{l}Q_{\mathrm{B}}(1)=2.372, p=.124 \\
Q_{\mathrm{W}}(22)=51.081, p=.0004\end{array}$} \\
\hline
\end{tabular}

The specification test did not reach the same results in the three models. Thus, assuming a mixed-effects model, the $Q_{\mathrm{W}}$ statistic calculated by Equation (17) reached statistical significance depending on the between-studies

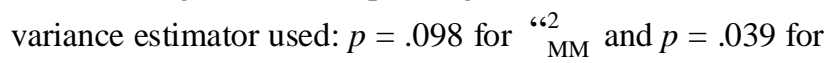
单 statistical significance. Therefore, depending on the statistical model assumed, we can conclude that the categorical model was misspecified or not. A more detailed analysis of the model specification consists in examining the separate $Q_{\mathrm{Wj}_{\mathrm{j}}}$ statistics calculated by Equation (16) in relation to each category of the moderator variable, in order to determine which categories were homogeneous around its mean effect size. Table 4 shows that the four effect sizes in the category áquasi-experimental designô seemed to be homogeneous around its mean, whereas the 20 effect sizes in the category áxperimental designô did not seem to be homogeneous.

Table 5. . Results of the weighted regression analysis applied on the publication year by assuming a random-effects model with 砶 and $\mathrm{Q}_{\mathrm{RML}}$, and for a fixed-effects model.

To illustrate how to analyze the influence of a continuous moderator variable on the effect sizes, we have selected the year of publication of the study and applied weighted regression analyses by assuming a fixed-effects or a mixed-effects model with two between-studies variance estimators ( GM $_{\text {MEML }}$ ). Table 5 presents the main results for the three models applied. By applying Equations (22) and (23), it is possible to test if there is a statistically significant relationship between the moderator variable and effect size. As Table 5 shows, in all three cases we found a statistically significant result for the $Q_{\mathrm{R}}$ and the $Z$ statistics. For example, by assuming a mixed-effects model with 舀M $=0.156$, calculated by Equation (20), we obtained $Q_{\mathrm{R}}(1)=4.439, p=.035$, or $Z=2.107, p=.035$. Note that in a simple regression model the statistical significance for testing the full model, $Q_{\mathrm{R}}$, coincides with that of the $Z$ test for the moderator variable. The positive sign of the
Sánchez-Meca, J., Marín-Martínez, F., (2010). Meta-analysis in Psychological Research. International Journal of Psychological Research, 3 (1), 150-162.

regression coefficient, $\dot{\beta}_{1}$, calculated by Equation (19), for the year of publication means that the most recent studies showed larger effect sizes than those of the older studies.

Table 5 also presents the results of testing the model specification with $Q_{\text {E }}$ statistic by applying Equation (21). In this case, depending on the statistical model applied the result for $Q_{\mathrm{E}}$ either reached or did not reach statistical significance. Thus, assuming a mixed-effects model the misspecification test did not reach statistical significance when using 潒 $\left[Q_{\mathrm{E}}(22)=28.830, p=.150\right]$, whereas it was marginally statistically significant when using REML $_{\text {RE }}$ $(p=.065)$. Assuming a fixed-effects model, the misspecification test was highly statistically significant ( $p=$ .0009).

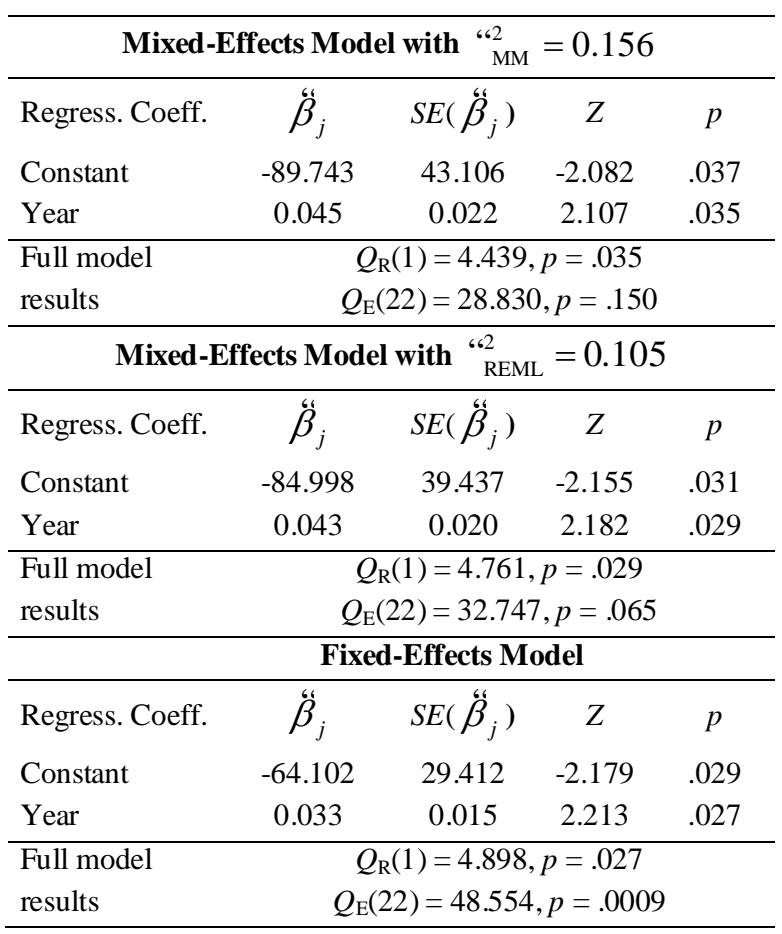

\section{Concluding Remarks}

Using meta-analysis to summarize the evidence about a given research problem has important advantages in comparison with narrative reviews. Firstly, meta-analyses can be replicated, as all decisions and steps carried out in their process are made explicit. Secondly, by applying statistical methods their conclusions are more reliable and precise. Thirdly, their emphasis on the effect size will contribute to ensuring that researchers pay more attention to the effect magnitude, resulting in a lesser interest in statistical significance tests. Finally, meta-analysis also contributes towards promoting Evidence-Based Practice in 
International Journal of Psychological Research, 2010. Vol. 3. No. 1.

ISSN impresa (printed) 2011-2084

ISSN electrónica (electronic) 2011-2079

Psychology, a new methodological approach that aims to encourage professionals to base their practice to the greatest extent possible on scientific evidence obtained from research.

Nevertheless meta-analysis has problems and limitations. On the one hand, the validity and accuracy of the results in a meta-analysis depend on the quality of the empirical studies integrated. If the single studies offer biased estimations of the effects, then the meta-analytic results will also be biased. An assessment of the methodological quality of the single studies is therefore one of the main requisites in any meta-analysis (cf. e.g., Valentine \& Cooper, 2008). In addition, meta-analysis can suffer publication bias if it is only based on published studies. As a consequence, an analysis of publication bias is essential in any meta-analysis (Rothstein, Sutton, \& Borenstein, 2005). Moreover, meta-analysis can suffer selection bias, when the selection criteria for including single studies in the meta-analysis are affected by theoretical or substantive preferences of the meta-analyst. A reliability analysis of the selection process of the studies should be therefore accomplished in order to avoid bias in this step of the meta-analysis. Finally, meta-analyses can be affected by reporting bias when the single studies only reported statistical data on the outcomes with positive results for the hypothesis tested. A detailed analysis of the design and the dependent variables included in the single studies should be carried out to assess whether studies are selectively reporting their statistical results.

As meta-analyses can suffer deficiencies and biases in their development and in their reporting practices, they should be read critically. To this end, several protocols and statements have been published that enable consumers of meta-analyses to assess their methodological quality. It is worth noting the recent publication of the PRISMA checklist (đ́Preferred Reported Items for Systematic reviews and Meta-Analyses; Moher, Liberati, Tetzlaff et al., 2009), a set of guidelines to assess the methodological quality in reporting practices of meta-analyses. Another endeavor along the same lines is the publication of the AMSTAR protocol for critical appraisal of meta-analyses (Shea, Grimshaw, Wells et al., 2007).

Finally, several software programs have been developed for carrying out statistical analyses in metaanalysis. David B. Wilson has developed macros for doing meta-analysis in SPSS, SAS, and STATA. The macros can be freely obtained from the web site http://mason.gmu.edu/ dwilsonb/ma.html. The Cochrane Collaboration has developed RevMan 5.0.22, another free program for carrying out meta-analysis that can be obtained from the web site of this Collaboration (www.cochrane.org). Finally, there is a commercial program Comprehensive Meta-analysis 2.0 (Borenstein,

International Journal of Psychological Research
Sánchez-Meca, J., Marín-Martínez, F., (2010). Meta-analysis in Psychological Research. International Journal of Psychological Research, 3 (1), 150-162.

Hedges, Higgins, \& Rothstein, 2005; www.metaanalysis.com).

This work has been supported by Ministerio de Ciencia e Innovación from the Spanish Government and by Fondo Europeo de Desarrollo Regional from the European Union (Project Number PSI2009-12172).

We would like to thank Juan Botella (Universidad Autónoma de Madrid, Spain) and José A. López-López (Universidad de Murcia, Spain) for their helpful suggestions to a previous version of the paper.

\section{REFERENCES}

Borenstein, M. J., Hedges, L. V., Higgins, J. P. T., \& Rothstein, H. (2005). Comprehensive Metaanalysis (Vers.2). Englewood Cliffs, NJ: Biostat, Inc.

Borenstein, M. J., Hedges, L. V., Higgins, J. P. T., \& Rothstein, H. R. (2009). Introduction to metaanalysis. Chichester, UK: Wiley.

Botella, J., \& Gambara, H. (2006). Doing and reporting a meta-analysis. International Journal of Clinical and Health Psychology, 6, 425-440.

Cohen, J. (1988). Statistical power analysis for the behavioral sciences ( $2^{\text {nd }}$ ed.). Hillsdale, $\mathrm{NJ}$ : Erlbaum.

Cook, T. D., Cooper, H., Cordray, D. S., Hartmann, H., Hedges, L. V., Light, R. J., Louis, T. A., \& Mosteller, F. (1992). Meta-analysis for explanation: A casebook. New York: Russell Sage Foundation.

Cooper, H. (2010). Research synthesis and meta-analysis: A step-by-step approach ( $3^{\text {rd }}$ ed.). Thousand Oaks, CA: Sage.

Cooper, H., Hedges, L. V., \& Valentine, J. C. (Eds.)(2009). The handbook of research synthesis and metaanalysis $\left(2^{\text {nd }}\right.$ ed.). New York: Russell Sage Foundation.

DerSimonian, R., \& Laird, N. (1986). Meta-analysis of clinical trials. Controlled Clinical Trials, 7, $177-$ 188.

Egger, M., Davey Smith, G., \& Altman, D. G. (Eds.) (2001). Systematic reviews in health care: Metaanalysis in context ( $2^{\text {nd }}$ ed.). London: BMJ Pub. Group.

Field, A. P. (2003). The problems of using fixed-effects models of meta-analysis on real-world data. Understanding Statistics, 2, 77-96.

Hartung, J. (1999). An alternative method for metaanalysis. Biometrical Journal, 41, 901-916.

Harwell, M. (1997). An empirical study of Hedges's homogeneity test. Psychological Methods, 2, 219231. 
International Journal of Psychological Research, 2010. Vol. 3. No. 1.

ISSN impresa (printed) 2011-2084

ISSN electrónica (electronic) 2011-2079

Hedges, L. V., \& Olkin, I. (1985). Statistical methods for meta-analysis. New York: Academic Press.

Hedges, L. V., \& Vevea, J. L. (1998). Fixed- and randomeffects models in meta-analysis. Psychological Methods, 3, 486-504.

Higgins, J. P. T., \& Green, S. (Eds.)(2008). Cochrane handbook for systematic reviews of interventions. Chichester, UK: Wiley-Blackwell.

Higgins, J. P. T., \& Thompson, S. G. (2002). Quantifying heterogeneity in a meta-analysis. Statistics in Medicine, 21, 1539-1558.

Hunter, J. E., \& Schmidt, F. L. (2004). Methods of metaanalysis: Correcting error and bias in research synthesis $\left(2^{\text {nd }}\right.$ ed.). Sage.

Konstantopoulos, S., \& Hedges, L. V. (2009). Fixed effects models. In H. Cooper, L. V. Hedges, \& J. C. Valentine (Eds.), The handbook of research synthesis and meta-analysis ( $2^{\text {nd }}$ ed.) (pp. 279293). New York: Russell Sage Foundation.

Lipsey, M. W., \& Wilson, D. B. (2001). Practical Metaanalysis. Thousand Oaks, CA: Sage

Littell, J. H., Corcoran, J., \& Pillai, V. (2008). Systematic reviews and meta-analysis. Oxford, UK: Oxford University Press.

Marín-Martínez, F., \& Sánchez-Meca, J. (2010). Weighting by inverse variance or by sample size in randomeffects meta-analysis. Educational and Psychological Measurement, 70, 56-73.

Moher, D., Liberatti, A., Tetzlaff, J., Altman D. G., and the PRISMA Group (2009). Preferred Reporting Items for Systematic reviews and Meta-Analyses: The PRISMA statement. PLOS Medicine, 6(7): e1000097. doi:10.1371journal.pmed.1000097.

Petticrew, M., \& Roberts, H. (2006). Systematic reviews in the social sciences: A practical guide. Malden, MA: Blackwell.

Raudenbush, S. W. (2009). Random effects models. In H. Cooper, L. V. Hedges, \& J. C. Valentine (Eds.), The handbook of research synthesis and metaanalysis ( $2^{\text {nd }}$ ed.) (pp. 295-315). New York: Russell Sage Foundation.

Rosa-Alcázar, A. I., Sánchez-Meca, J., Gómez-Conesa, A., \& Marín-Martínez, F. (2008). Psychological treatment of obsessive-compulsive disorder: A meta-analysis. Clinical Psychology Review, 28, 1310-1325.

Rosenthal, R. (1995). Writing meta-analytic reviews. Psychological Bulletin, 118, 183-192.

Rothstein, H. R., Sutton, A. J., \& Borenstein, M. (Eds.) (2005). Publication bias in meta-analysis: Prevention, assessment, and adjustments. Chichester, UK: Wiley.

Sánchez-Meca, J., \& Marín-Martínez, F. (1997). Homogeneity tests in meta-analysis: A Monte Carlo comparison of statistical power and Type I error. Quality and Quantity, 31, 385-399.
Sánchez-Meca, J., Marín-Martínez, F., (2010). Meta-analysis in Psychological Research. International Journal of Psychological Research, 3 (1), 150-162.

Sánchez-Meca, J., \& Marín-Martínez, F. (1998). Weighting by inverse-variance or by sample size in metaanalysis: A simulation study. Educational and Psychological Measurement, 58, 211-220.

Sánchez-Meca, J., \& Marín-Martínez, F. (2008). Confidence intervals for the overall effect size in random-effects meta-analysis. Psychological Methods, 13, 31-48.

Sánchez-Meca, J., \& Marín-Martínez, F. (2010). Metaanalysis. In P. Peterson, E. Baker, \& B. McGaw (Eds.), International encyclopedia of education, Vol. 7 ( $3^{\text {rd }}$ ed.) (pp. 274-282). Oxford: Elsevier

Sánchez-Meca, J., Marín-Martínez, F., \& Chacón-Moscoso, S. (2003). Effect-size indices for dichotomized outcomes in meta-analysis. Psychological Methods, 8, 448-467.

Schmidt, F. L., Oh, I.-S., \& Hayes, T. L. (2009). Fixed versus random effects models in meta-analysis: Model properties and an empirical comparison of difference in results. British Journal of Mathematical and Statistical Psychology, 62, 97128.

Shea, B. J., Grimshaw, J. M., Wells, G. A., Boers, M., Andersson, N., Hamel, C., Porter, A. C., Tugwell, P., Moher, D., \& Bouter, L. M. (2007). Development of AMSTAR: A measurement tool to assess the methodological quality of systematic reviews. BMC Medical Research Methodology, 7. doi:10.1186/1471-2288-7-10

Sidik, K., \& Jonkman, J. N. (2003). On constructing confidence intervals for a standardized mean difference in meta-analysis. Communications in Statistics: Simulation \& Computation, 32, 11911203.

Sidik, K, \& Jonkman, J. N. (2006). Robust variance estimation for random effects meta-analysis. Computational Statistics and Data Analysis, 50, 3681-3701.

Sutton, A. J., \& Higgins, J. P. T. (2008). Recent developments in meta-analysis. Statistics in Medicine, 27, 625-650.

Thompson, S. G., \& Sharp, S. J. (1999). Explaining heterogeneity in meta-analysis: A comparison of methods. Statistics in Medicine, 18, 2693-2708.

Valentine, J. C., \& Cooper, H. (2008). A systematic and transparent approach for assessing the methodological quality of intervention effective research: The Study Design and Implementation Assessment Device (Study DIAD). Psychological Methods, 13, 130-149.

Viechtbauer, W. (2005). Bias and efficiency of metaanalytic variance estimators in the random-effects model. Journal of Educational and Behavioral Statistics, 30, 261-293. 